\section{A fly's ultimate con}

SIR - Many aberrant insects are known from colonies of social insects ${ }^{1}$, but few as bizarre as that reported here. In the rainforest of Malaysia, in 1994, two of us (A.W. and U.M.) collected an entire bivouac of a driver ant, an undescribed species of Aenictus Shuckard, situated in the fork of a tree. It was formed by ants that had interlocked their tarsal claws to form a temporary nest-like structure. From this bivouac, one of us (K.R.) recovered 104 specimens of an unidentified insect (Figs 1, 2), 80 Diptera larvae of the family Phoridae, 57,100 worker ants and a single queen. The latter was in a non-physogastric state, indicating that the colony was in its migratory phase.

The unidentified insects were flightless, legless (apart from reduced coxae and trochanters), and had vermiform abdomens lacking tergites $2-7$, but bearing strong setae. Despite the larviform appearance, the structure of the head and the abdominal terminalia indicated that they are adults which closely resemble the larvae of their ant host. The form of the proboscis, antennae and thorax (Fig. 1a) immediately excluded them from Hymenoptera and identified them as Diptera.

After failing to match these flies to any known myrmecophilous genera, a sample was sent to David Kistner (California State University, Chico), who, in collaboration with A. and M. Newton (Field Museum of Natural History, Chicago), concluded that they might be highly aberrant Phoridae. This was confirmed by one of us (R.H.L.D.) from the structure of the antennae and clypeo-cibarium.

Many myrmecophilous and termitophilous Phoridae possess flightless

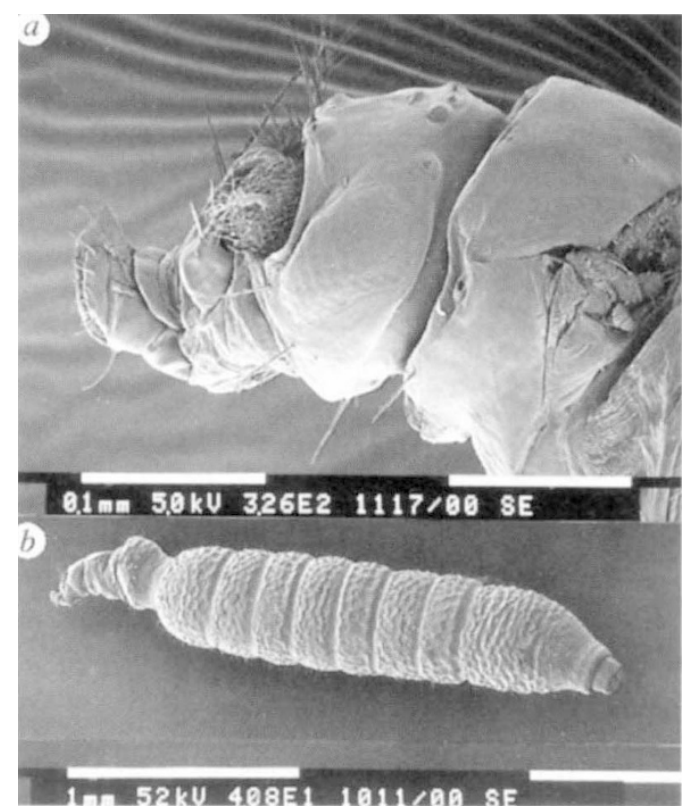

FIG. 1 Left face of legless fly. a, Head and thorax; $b$, whole fly. females whose wings are either absent or reduced, or whose membranes are shed when the fly enters its host's nest. They are normally transported by the males to the colonies of their hosts during mating ${ }^{2}$. All these aberrant phorids possess legs. Our specimens are all mature females, gravid with eggs (Fig. $2 a$ ). These eggs are also examples of mimicry, closely resembling those of their ant host. The presence of sperm, in a spermathecal pocket discharging into the atrium, indicates that the species has males.

Vestigial legs are previously unrecorded in Phoridae, and are exceedingly rare in adult Diptera. In the bat parasites Ascodipteron Adensamer (Streblidae), the newly emerged females possess both wings and legs, but, on invading their hosts, they shed the wings and the legs beyond their trochanters ${ }^{3}$. The closest parallel to our bizarre phorid is the marine midge Pontomyia Edwards (Chironomidae), whose females possess vermiform abdomens and lack wings, halteres and front legs at the time of emergence. Their middle and hind legs are vestigial, being reduced to coxae, trochanters and, in some cases, abbreviated femora as well. In one species there are also vestigial tibiae ${ }^{4.5}$.

In our phorid, the middle and hind coxae are the most developed, but the endoskeleton associated with these coxae is not fully developed. Thus, the metafurca is not fully sclerotized ventrally and lacks any sclerotized connections with the mesofurca (Fig. 2b). Such an incomplete endoskeleton would be unlikely to allow proper functioning of the legs if they were still present. Similarly, the exoskeleton of the thorax shows incomplete sclerotization and seems to be insufficiently fused to allow normal flight or walking. Thus, the mesonotal and metanotal phragmata are not fused, so that the latter appears detached. The only representatives of wings are the tegulae, basicostas and roots of the costas (Fig. 1a). The halteres are vestigial, with uninflated knobs. These reduced structures represent a striking case of heterochrony, a phenomenon associated with other aberrant Phoridae and most strongly manifested by some of the termitophilous Termitoxeniinae $e^{2,6}$.

This phorid will be assigned to a new genus and fully described else-

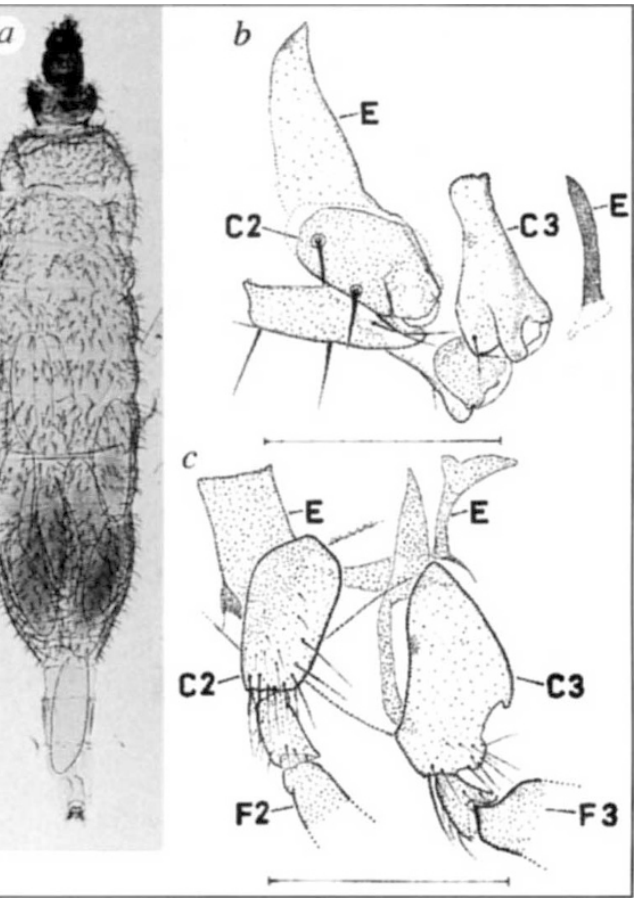

G. 2 Legless fly and its leg rudiments compared with ose of a normal phorid. a, Whole fly showing mature ggs within. $b, c$, Middle and hind coxae of legless horid fly $(b)$ and Metopina oligoneura $(c)$. C2, middle oxae; $\mathrm{C} 3$, hind coxae; E, endoskeleton (including mesorca to left and metafurca to right); F2, base of mid mur; F3, base of hind femur. Scale bars, $0.1 \mathrm{~mm}$.

where $^{7}$. Evidently, the flies and their larvae are fully integrated into the ant colony and totally deceive their hosts. Both must be producing pheromones that mimic those of their host. In standard keys to insect orders ${ }^{8}$, the lack of legs would cause these adult flies to be identified as anomalous larvae of Diptera or other endopterygote insects. It is probable, therefore, that others have collected these highly aberrant flies, but have been unsuccessful in identifying them*

\section{A. Weissflog}

\section{U. Maschwitz}

Zoologisches Institut,

Johann Wolfgang Goethe-Universität,

60054 Frankfurt am Main, Germany

R. H. L. Disney

University Department of Zoology,

University of Cambridge,

Cambridge CB2 3EJ, UK

\section{K. Rościszewski}

Staatliches Museum für Naturkunde, Karlsruhe, D-76042 Karlsruhe, Germany

1. Kistner, D. H. in Social Insects Vol. 3 (ed. Hermann, H. R.) 1-244 (Academic, New York, 1982).

2. Disney, R. H. L. Scuttle Flies: The Phoridae (Chapman \& Hall, London, 1994)

3. Muir, F. Bull. Mus. comp. Zool. 54, 349-366 (1912).

4. Edwards, F. W. Proc zool. Soc. Lond. 51/52, 779-806 (1926).

5. Tokunaga, M. Mem. Coll. Agric. Kyoto Univ. 19, 1-56 (1932).

6. Disney, R. H. L. Bonn. zool. Beitr. (in the press)

7. Disney, R. H. L. Sociobiology (in the press).

8. Tilling, S.M. Fld Stud. 6, 695-766 (1987).

* If others have collected similar legless flies but failed to identify them to their order or family, R.H.L.D. would be pleased to examine such specimens. 